\title{
Introduction to the Taiwan Biophysical Society
}

\author{
Ping-Chiang Lyu ${ }^{1}$ (i)
}

Received: 28 March 2019 / Accepted: 24 April 2019 / Published online: 22 May 2019

(C) International Union for Pure and Applied Biophysics (IUPAB) and Springer-Verlag GmbH Germany, part of Springer Nature 2019

The Taiwan Biophysical Society (Biophysical Society of Taiwan, R.O.C.) started operation in 1995 with the understanding that enhancement of biophysical knowledge benefits the development of life science and biotechnology-based research in Taiwan. Thus, one of the principal aims of the Biophysical Society of Taiwan is to help facilitate the introduction and promotion of the most recent advances in biophysical research to the Taiwan scientific community. Toward this purpose, the society stages conferences, assists scientists to communicate their results, and runs workshops to educate scientists in outside fields about biophysics. To date, the Biophysical Society of Taiwan has successfully affiliated the local biophysical scientists and, in the process of doing so, has become one of the largest scientific societies in Taiwan. Currently, we have over 400 members, made up of principal investigators, professors, junior scholars, students, and industrial partners.

The key activity of the Taiwan Biophysical Society is the annual conference, where we invite local and international speakers to present their cutting-edge research in a wide range of biophysical fields. The conference is international and friendly to foreigner participants, with all lectures presented in English. The annual conference provides opportunities for the participants to share their research results and to establish collaborations. The conference also serves as a platform for students and junior scholars to publish their results. Typically,

This article is part of a Special Issue dedicated to the '2018 Joint Conference of the Asian Biophysics Association and Australian Society for Biophysics' edited by Kuniaki Nagayama, Raymond Norton, Kyeong Kyu Kim, Hiroyuki Noji, Till Böcking, and Andrew Battle.

Ping-Chiang Lyu

pclyu@mx.nthu.edu.tw

1 Department of Medical Sciences, National Tsing Hua University, Hsinchu, Taiwan the number of participants is more than 250 . The most recent conference (the 24th biophysics conference) will be held from 29 May to 1 June 2019, in Ilan, Taiwan.

The Taiwan Biophysical Society maintains relations with international organizations. The society is one of the seven founding members of the Asian Biophysical Association (ABA). It hosted the fourth East Asian Biophysics Symposium (4th EABS) in 2003 in Taipei and is preparing to organize the 11th ABA symposium in 2021. The Taiwan Biophysical Society is an adhering member of IUPAB. We also represent the protein research field of Taiwan by serving council membership in the Asia Pacific Protein Association (APPA). The communications with other neighboring nations are intense, with bilateral meetings frequently held.

The current president is Dr. Ping-Chiang Lyu and the secretary-general is Dr. Shih-Che Sue, with both scientists located in the Institute of Bioinformatics and Structural Biology, National Tsing Hua University. The official address of the Biophysical Society of Taiwan is at No. 128, Academia Road, Section 2, Nankang, Taipei 11529, Taiwan. The contacted e-mail for the society is biophys@gate.sinica.edu.tw. More society information can be found on this website: http://biophys.sinica.edu. tw. The cost of regular membership is around 40 US dollars per year.

\section{Compliance with ethical standards}

Conflict of interest Ping-Chiang Lyu declares that he has no conflict of interest.

Ethical approval This article does not contain any studies with human participants or animals performed by the author.

Publisher's note Springer Nature remains neutral with regard to jurisdictional claims in published maps and institutional affiliations. 